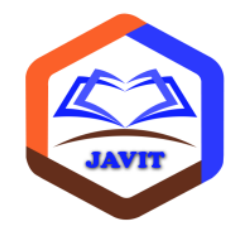

JURNAL VOKASI INFORMATIKA

(JAVIT)

Terbit online pada laman web jurnal: http://javit.ppj.unp.ac.id

DOI: https://doi.org/10.24036/javit.v1i2.22

ISSN: $2775-6807$

Vol. 1 No. 2 (2021) $49-52$

\title{
Kontribusi Cara Belajar dan Media Pembelajaran Terhadap Hasil Belajar Peserta Didik Pada Mata Pelajaran Merakit Personal Komputer Kelas X Teknik Komputer Jaringan di SMK Negeri 6 Padang
}

\author{
${ }^{1, *}$ Rudi Khaizar Putra, ${ }^{2}$ Legiman Slamet \\ ${ }^{1}$ Pendidikan Teknik Informatika dan Komputer, Fakultas Teknik, Universitas Negeri Padang \\ ${ }^{2}$ Teknik Elektronika, Fakultas Teknik, Universitas Negeri Padang \\ *Coressponding author e-mail: rudiptr96@gmail.com
}

\begin{abstract}
Abstrak
Hasil belajar siswa kelas X Teknik Komputer Jaringan SMK Negeri 6 Padang yang rendah menjadi masalah utama yang melatar belakangi penelitian ini. Sebesar 48,84\% siswa memperoleh nilai hasil belajar di bawah Kriteria Ketuntasan Minimal (KKM). Dari rentang 0-100, nilai KKM mata pelajaran merakit personal komputer yang ditetapkan sekolah ialah sebesar 75. Penelitian ini bertujuan untuk mengungkapkan kontribusi cara belajar serta media pembelajaran pada hasil belajar mata pelajaran merakit personal komputer kelas X Teknik Komputer Jaringan di SMK Negeri 6 Padang. Jenis penelitian ini adalah deskriptif korelasional. Sampel diambil secara acak dengan teknik porposional random sampling. Data cara belajar dan media pembelajaran dikumpulkan melalui angket dengan skala likert yang sudah melalui pengujian validitas dan realibilitas. Dengan metode statistik berbantuan Microsoft Excel 2007 dan SPSS Version 16 data dianalisis dan diperoleh hasil bahwa cara belajar dan media belajar hanya menyumbang $1,1 \%$ terhadap hasil belajar. Dengan hasil ini, diperoleh kesimpulan bahwa cara belajar dan media pembelajaran memiliki kontribusi atas hasil belajar, semakin baik cara belajar siswa dan penggunaan media pada proses pembelajaran maka akan semakin baik juga hasil belajar yang akan didapat. Meski demikian tetap diperlukan perhatian dari seluruh elemen terhadap penggunaan media terutama internet.
\end{abstract}

Kata kunci : Cara Belajar, Media Pembelajaran, Hasil Belajar, Deskriptif Korelasional, Porposional Random Sampling.

(C) Lisensi: Creative Commons Attribution 4.0 International (CC BY 4.0) 


\section{Pendahuluan}

Pendidikan memegang peranan penting dalam upaya meningkatkan kualitas manusia, baik dalam kemampuan sosial, spiritual, intelektual maupun kemampuan profesional, karena manusia merupakan kekuatan utama pembangunan. Kegiatan pembelajaran merupakan inti dari proses pendidikan yang dalam pelaksanaannya bukan hanya mentransfer ilmu saja, tetapi juga menanamkan sikap dan nilai pada diri peserta didik. Agar kegiatan pembelajaran dapat berhasil secara maksimal maka di butuhkan cara belajar yang efektif dan efisien. Cara belajar merupakan kegiatan belajar yang seharusnya dilakukan dalam mempelajari sesuatu dalam situasi belajar tertentu[1]". Kegiatan belajar yang dilakukan meliputi bagaimana peserta didik mempersiapkan pembuatan jadwal belajar, mengikuti pelajaran di sekolah, membaca dan membuat buku catatan, mengulangi bahan pelajaran, mengerjakan tugas di sekolah, dan cara peserta didik mengikuti ujian. Kualitas cara belajar menentukan kualitas hasil belajar yang diperoleh. Semakin tepat penggunaan cara belajar, semakin memuaskan hasil belajar yang diperoleh, begitupun sebaliknya. Oleh sebab itu hendaknya peserta didik mempunyai cara belajar yang baik, agar hasil belajar yang diperoleh juga baik dan memuaskan.

Hasil belajar merupakan kemampuan yang dimiliki peserta didik setelah ia menerima pengalaman belajarnya"[2]. Hasil belajar dapat dilihat dari kemampuannya melakukan sesuatu kegiatan baru yang bersifat menetap dari pada yang dilakukan sebelumnya sebagai akibat atau hasil dari interaksi peserta didik dengan lingkungan"[3]. Hasil_belajar diartikan sebagai tingkat penguasaan yang dicapai oleh peserta didik pada proses kegiatan belajar mengajar. Perolehan hasil belajar biasanya disesuaikan dengan program penilaian yang telah lebih dulu ditetapkan. Tingkat pengetahuan dan pemahaman peserta didik dalam sebuah pelajaran diukur melalui hasil belajarnya. Untuk mendapatkan hasil belajar yang lebih maksimal lagi peserta didik dapat memanfaatkan media pembelajaran baik yang tersedia di sekolah maupun diluar sekolah.

\section{Tinjauan Pustaka}

\subsection{Media Pembelajaran}

Media pembelajaran merupakan segala bentuk perangsang dan alat yang disediakan guru guna menciptakan dorongan terhadap peserta didik agar belajar dengan benar, mudah, tepat, cepat, dan menghindari verbalisme[4]. Media pembelajaran ialah keseluruhan alat dan bahan yang bisa dimanfaatkan untuk mencapai tujuan pendidikan, misalnya seperti majalah, koran, buku, televisi, radio, dan semacamnya [5].
Salah satu media yang sangat membantu peserta didik dalam pembelajaran adalah internet. Internet merupakan perpustakaan raksasa dunia, karena didalam internet terdapat miliayaran informasi sehingga kita dapat menggunakan informasi tersebut [6]. Internet merupakan sebuah jaringan besar yang terdiri atas bermacam-macam jaringan pendidikan dan riset yang di dalamnya terdapat jutaan komputer yang saling terhubung [7]. Pemanfaatan internet sebagai media pembelajaran mengkondisikan peserta didik untuk belajar secara mandiri. belajar mandiri adalah belajar dengan bantuan minimal orang lain atau media sebagia perantara [8].

Keberhasilan peserta didik dalam belajar sangat tergantung kepada pencapaian kompetensi peserta didik pada setiap mata pelajarannya. Pencapaian kompetensi peserta didik sangat ditentukan oleh nilai KKM yang telah ditetapkan. Menurut Dirjen Dikdasmen No.1321/c4/MN/2004 tentang Pengkajian Standar Ketuntasan Minimal, berdasarkan petunjuk dari Badan Standar Nasional Pendidikan (BSNP) tahun 2006 setiap sekolah boleh menentukan standar ketuntasan sekolahnya masing masing.

Tingkat keberhasilan peserta didik di Kelas X Teknik Komputer Jaringan di SMK Negeri 6 Padang pada mata pelajaran Merakit Personal Komputer memperoleh nilai $\geq 75,00$ sebesar $50,85 \%$ sebanyak 36 orang siswa. Hasil belajar < 75,00 sebanyak 29 orang siswa dengan presentase sebesar $49,15 \%$ dari 59 orang siswa. Hal ini dapat terjadi karena belum maksimalnya cara belajar yang siswa lakukan dan pemanfaatan media pembelajaran oleh siswa. Dengan melihat dari latar belakang masalah di atas penulis tertarik untuk melakukan penelitian yang berjudul: "Kontribusi Cara Belajar dan Media Pembelajaran Terhadap Hasil Belajar Siswa Pada Mata Pelajaran Merakit Personal Komputer Kelas X Teknik Komputer Jaringan di SMK Negeri 6 Padang".

\subsection{Cara Belajar}

Cara belajar adalah bagaimana siswa melakukan kegiatan belajar. Kegiatan pembelajaran yang dilakukan meliputi bagaimana siswa mempersiapkan diri untuk belajar, mengikuti pelajaran, kegiatan belajar mandiri, pola belajar dan bagaimana siswa mengikuti ujian. Kualitas cara belajar menentukan kualitas hasil belajar yang diperoleh. Oleh karena itu, siswa harus memiliki cara belajar yang baik, agar hasil belajar yang diperoleh juga baik dan memuaskan.

Setelah siswa dapat memilih dan memposisikan dirinya dalam kondisi yang kondusif, siswa perlu menggunakan metode pembelajaran yang efektif. 
Berdasarkan kondisi pembelajaran, metode pembelajaran meliputi:

1. Cara belajar di rumah

2. Cara belajar di sekolah dan

3. Cara belajar bersama (kelompok)Hasil Belajar

2.3. Hasil Belajar

Hasil belajar diartikan sebagai tingkat penguasaan yang dicapai siswa dalam mengikuti program belajar mengajar. Perolehan hasil belajar biasanya disesuaikan dengan program penilaian yang telah ditentukan.

Dengan hasil belajar tersebut, kita dapat melihat kemajuan siswa. Dalam pembelajaran merakit perangkat komputer, hasil belajar dapat dijadikan sebagai acuan dan tolak ukur untuk mengetahui tingkat keberhasilan siswa dalam mengetahui dan memahami suatu pelajaran.

\section{Metode Penelitian}

Penelitian ini merupakan penelitian deskriptif yang bersifat korelasional. Penelitian ini bertujuan untuk mendeskripsikan dan mengungkap seberapa besar kontribusi variabel bebas terhadap variabel terikat. Variabel bebas terdiri dari cara belajar dan media pembelajaran, sedangkan hasil belajar peserta didik menjadi variabel terikat. Teknik pengambilan sampel menggunakan proportional random sampling, yang berarti sampel diambil dari semua anggota populasi dilakukan dengan cara acak tanpa melihat tingkatan yang ada dalam populasi. Untuk menentukan julah sampel digunakan rumus:

$$
n=\frac{N}{N \cdot d^{2}+1}
$$

Dimana

$n$ = Jumlah sampel

$\mathrm{N}$ = Jumlah populasi

$\mathrm{d} 2=$ Presesi yang ditetapkan (persen kelonggaran karena kesalahan pengambilan sampel 10\%)[9].

Tabel 1. Populasi Penelitian

\begin{tabular}{ccc}
\hline No & Kelas & Jumlah Peserta didik \\
\hline 1 & X TKJ1 & 36 \\
\hline 2 & X TKJ2 & 35 \\
\hline & Jumlah & 71 \\
\hline
\end{tabular}

Sumber Data : Sekolah Menengah Kejuruan Negeri 6 Padang.

Berdasarkan hal diatas didapatkan jumlah sampel penelitian sebanyak 32 peserta didik. Dengan menggunakan nilai presisi sebesar $10 \%$ didapatkan populasi sebanyak 71 peserta didik, kemudian dilakukan pengambilan sampel secara acak dengan formula:

$$
n_{i}=\frac{N_{i}}{N} \times n
$$

Keterangan

$\mathrm{n}_{\mathrm{i}}=$ Jumlah sampel menurut stratum (populasi) $\mathrm{n}=$ Jumlah sampel seluruhnya

$\mathrm{N}_{\mathrm{i}}=$ Jumlah populasi menurut stratum

$\mathrm{N}=$ Jumlah populasi seluruhnya[10]

Dari formula tersebut didapat sampel penelitian dengan jumlah sebagaimana ditunjukkan tabel 2 .

\begin{tabular}{ccc}
\multicolumn{3}{c}{ Tabel 2. Sampel Penelitian } \\
\hline No & Kelas & Sampel Penelitian \\
\hline 1 & X TKJ1 & 16 \\
\hline 2 & X TKJ2 & 16 \\
\hline
\end{tabular}

\section{Hasil dan Pembahasan}

Setelah pelaksanaan uji coba, hasil pengujian diuji validitasnya dengan bantuan software microsoft excel 2007 dan SPSS Statistic. Sebesar 5\% taraf siginifikan diterapkan dalam penelitian ini, sebagaimana ditunjukkan tabel 3 dan tabel 4.

Tabel 3. Hasil Uji Validitas Cara Belajar X1

\begin{tabular}{cccc}
\hline Item & Thitung & Ttabel & Valid \\
\hline Item_1 & 0,461 & 0,456 & Valid \\
\hline Item_2 & 0,612 & 0,456 & Valid \\
\hline Item_3 & 0,574 & 0,456 & Valid \\
\hline Item_4 & 0,596 & 0,456 & Valid \\
\hline Item_5 & 0,273 & 0,456 & Tidak Valid \\
\hline Item_6 & 0,482 & 0,456 & Valid \\
\hline Item_7 & 0,140 & 0,456 & Tidak Valid \\
\hline Item_8 & 0,445 & 0,456 & Tidak Valid \\
\hline Item_9 & 0,709 & 0,456 & Valid \\
\hline Item_10 & 0,711 & 0,456 & Valid \\
\hline Item_11 & 0,158 & 0,456 & Tidak Valid \\
\hline Item_12 & 0,517 & 0,456 & Valid \\
\hline Item_13 & 0,486 & 0,456 & Valid \\
\hline Item_14 & 0,701 & 0,456 & Valid \\
\hline Item_15 & 0,283 & 0,456 & Tidak Valid \\
\hline Item_16 & 0,146 & 0,456 & Tidak Valid \\
\hline Item_17 & 0,435 & 0,456 & Tidak Valid \\
\hline Item_18 & 0,271 & 0,456 & Tidak Valid \\
\hline Item_19 & 0,025 & 0,456 & Tidak Valid \\
\hline Item_20 & 0,547 & 0,456 & Valid \\
\hline Item_21 & 0,315 & 0,456 & Tidak Valid \\
\hline Item_22 & 0.611 & 0,456 & Valid \\
\hline Item_23 & 0,645 & 0,456 & Valid \\
\hline Item_24 & 0,064 & 0,456 & Tidak Valid \\
\hline Item_25 & 0,633 & 0,456 & Valid \\
\hline Item_26 & 0,390 & 0,456 & Tidak Valid \\
\hline Item_27 & 0,109 & 0,456 & Tidak Valid \\
\hline Item_28 & 0,239 & 0,456 & Tidak Valid \\
\hline Item_29 & 0,454 & 0,456 & Tidak Valid \\
\hline Item_30 & 0,537 & 0,456 & Valid \\
\hline & & &
\end{tabular}

Berdasarkan tabel 3, 15 dari 30 item pernyataan pada variabel X1 (cara belajar) dinyatakan valid, sementara 15 item sisanya dinyatakan gugur. 15 item yang dinyatakan gugur tersebut meliputi item nomor $5,7,8,11,15,16,17,18,19,21,24,26,27$, 28,29 . Dengan ttabel $=0,456$ ! pada taraf nyata 0.05. Uji coba validitas cara belajar (X1) ditunjukkan tabel 4.

Tabel 4. Hasil Uji Validitas Media Pembelajaran (X2)

\begin{tabular}{cccc}
\hline Item & Thitung & Ttabel & Valid \\
\hline Item_1 & 0,354 & 0,456 & T Valid \\
\hline
\end{tabular}




\begin{tabular}{|c|c|c|c|}
\hline Item & Thitung & Ttabel & Valid \\
\hline Item_2 & 0,387 & 0,456 & $\mathrm{~T}$ Valid \\
\hline Item_3 & 0,010 & 0,456 & $\mathrm{~T}$ Valid \\
\hline Item_4 & 0,541 & 0,456 & Valid \\
\hline Item_5 & 0,557 & 0,456 & Valid \\
\hline Item_6 & 0,590 & 0,456 & Valid \\
\hline Item_7 & 0,400 & 0,456 & $\mathrm{~T}$ Valid \\
\hline Item_8 & 0,399 & 0,456 & $\mathrm{~T}$ Valid \\
\hline Item_9 & 0,507 & 0,456 & Valid \\
\hline Item_10 & 0,399 & 0,456 & $\mathrm{~T}$ Valid \\
\hline Item_11 & 0,561 & 0,456 & Valid \\
\hline Item_12 & 0,118 & 0,456 & $\mathrm{~T}$ Valid \\
\hline Item_13 & 0,261 & 0,456 & $\mathrm{~T}$ Valid \\
\hline Item_14 & 0,562 & 0,456 & Valid \\
\hline Item_15 & 0,369 & 0,456 & T Valid \\
\hline Item_16 & 0,361 & 0,456 & $\mathrm{~T}$ Valid \\
\hline Item_17 & 0,674 & 0,456 & Valid \\
\hline Item_18 & 0,013 & 0,456 & $\mathrm{~T}$ Valid \\
\hline Item_19 & 0,418 & 0,456 & $\mathrm{~T}$ Valid \\
\hline Item_20 & 0,122 & 0,456 & $\mathrm{~T}$ Valid \\
\hline Item_21 & 0,731 & 0,456 & Valid \\
\hline Item_22 & 0,369 & 0,456 & $\mathrm{~T}$ Valid \\
\hline Item_23 & 0,646 & 0,456 & Valid \\
\hline Item_24 & 0,798 & 0,456 & Valid \\
\hline Item_25 & 0,610 & 0,456 & Valid \\
\hline Item_26 & 0,801 & 0,456 & Valid \\
\hline Item_27 & 0,480 & 0,456 & Valid \\
\hline Item_28 & 0,150 & 0,456 & T Valid \\
\hline Item_29 & 0,027 & 0,456 & $\mathrm{~T}$ Valid \\
\hline Item_30 & 0,022 & 0,456 & T Valid \\
\hline Item_31 & 0,632 & 0,456 & Valid \\
\hline Item_32 & 0,752 & 0,456 & Valid \\
\hline Item_33 & 0,400 & 0,456 & $\mathrm{~T}$ Valid \\
\hline Item_34 & 0,608 & 0,456 & Valid \\
\hline Item_35 & 0,187 & 0,456 & $\mathrm{~T}$ Valid \\
\hline Item_36 & 0,485 & 0,456 & Valid \\
\hline Item_37 & 0,255 & 0,456 & $\mathrm{~T}$ Valid \\
\hline Item_38 & 0,549 & 0,456 & Valid \\
\hline Item_39 & 0,446 & 0,456 & $\mathrm{~T}$ Valid \\
\hline Item_40 & 0,012 & 0,456 & $\mathrm{~T}$ Valid \\
\hline
\end{tabular}

Sementara itu, valiabel X2 (media pembelajaran), berdasarkan tabel 10 terdapat 18 item dari 40 item yang dinyatakan valid dan 22 item sisanya dinyatakn gugur. 22 item yang gugur meliputi item nomor $1,2,3,7,8,10,12,13,15,16$, $18,19,20,22,28,29,30,33,35,37,39,40$. Dengan ttabel $=0,456$ ! pada taraf signifikan 0.05 .

Berdasarkan uji asumsi klasik multikolinearitas dan heteroskedastisitas menunjukkan bahwa data yang digunakan tidak terdapat korelasi antar variabel dan memiliki sebaran data. Hasil tersebut dapat dilihat pada lampiran (10), hal ini dengan ditunjukkan bahwa nilai VIF \pm 5 dan sebaran data nya bervariasi dilihat dengan tidak adanya pola pada uji heteroskedastisitas.

Melalui analisis hasil pengujian anova, didapat data bahwa tidat terdapat pengaruh yang signifikan dari cara_belajar dan penggunaan media pembelajaran secara bersama-sama terhadap hasil!belajar ( $\mathrm{P}>0,05)$. Uji t menunjukkan bahwa secara parsial, cara belajar dan media belajar juga tidak memiliki pengaruh signifikan terhadap hasil belajar $(\mathrm{P}>0,05)$. Untuk melihat hubungan cara belajar dan media pembelajaran terhadap hasil pembelajaran dilakukan Uji Regresi Berganda untuk melihat persamaan antar variabel. Persamaan yang didapat pada penelitian ini yaitu $\mathbf{Y}=\mathbf{4 , 3 4 4}+$ 0,040X1 - 0,052X2. Interpretasi dari hasil persamaan tersebut yaitu ada hubungan yang positif yakni antara cara belajar dan hasil belajar yang artinya jika menambahkan $1 \%$ cara belajar maka hasil belajar meningkat $0,040 \%$, sedangkan dengan media pembelajaran memiliki hubungan yang negatif dimana jika menambahkan $1 \%$ maka hasil belajar berkurang atau menurun $0,052 \%$.

Berdasarkan hasil koefisien determinasi R2 cara belajar dan media pembelajaran hanya menyumbang $1,1 \%$ terhadap hasil belajar sedangkan 98,9\% lainnya berasal dari faktor lain. Keberhasilan proses belajar dipengaruhi oleh banyak faktor lain yang salling berpengaruh. Faktor lain tersebut meliputi: kurangnya konsentrasi, tidak mencatat pelajaran, tidak mengulang kembali pelajaran di rumah, dan jadwal pembelajaran beserta pelaksanaan pembelajaran.

\section{Kesimpulan}

Dari hasil penelitian diperoleh data bahwa terdapat pengaruh sebesar $1,1 \%$ dari cara belajar peserta didik dan media pembelajaran terhadap hasil belajar peserta didik kelas $\mathrm{X}$ Teknik Komputer Jaringan SMK Negeri 6 Padang Tahun Pembelajaran 2019/2020. Dari uji anova yang dilakukan, hasilnya memperlihtakan bahwa secara parsial tidak terdapat signifikansi pengaruh dari cara belajar dan penggunaan media pembelajaran atas hasil belajar peserta didik $(\mathrm{P}>0,05)$. Selain itu juga, berdasarkan hasil koefisien determinasi R2 cara belajar dan penggunaan media pembelajaran bisa meningkatkan hasil belajar peserta didik sebesar $1,1 \%$.

Bahan masukan bagi Kepala SMK Negeri 6 Padang dalam menentukan arah dan kebijakan dalam upaya peningkatan mutu pendidikan

\section{Daftar Rujukan}

[1] Agri Noor Hidayat. (2015). Yuk Belajar Efektif. Surabaya: CV. SMART

[2] Anas Sudijono. (2009). Pengantar Evaluasi Pendidikan. Jakarta: PT_Raja_Grafindo_Persada.Azhar_Arsyad. (2009). Media pembelajaran. Jakarata: Rajawali_Pers.

[3] Bambang_Warsita (2008). Teknologi Pembelajaran_Landasan danAplikasinya. Jakarta: PT_Renika_Cipta.

[4] Dalyono. (2010). _Psikologiᄀ_Pendidikan. Jakarta: PT_Rineka_Cipta. 